\title{
Association between social relationships and survival of Swiss octogenarians. A five-year prospective, population-based study
}

\author{
Edith Guilley ${ }^{1}$, Stephanie Pin ${ }^{1}$, Dario Spini ${ }^{2}$, Christian Lalive d'Epinay ${ }^{1,3}$, François Herrmann ${ }^{4}$, and \\ Jean-Pierre Michel ${ }^{1,4}$ \\ ${ }^{1}$ Centre for Interdisciplinary Gerontology, University of Geneva, Geneva, ${ }^{2}$ Lemanic Institute for Life Course \\ and Life Style Studies, University of Lausanne, Lausanne, ${ }^{3}$ Department of Sociology, University of Geneva, \\ ${ }^{4}$ Department of Rehabilitation and Geriatrics, University Hospital of Geneva, Geneva, Switzerland
}

ABSTRACT. Background and aims: Data from the literature reveal the contrasting influences of family members and friends on the survival of old adults. On one hand, numerous studies have reported a positive association between social relationships and survival. On the other, ties with children may be associated with an increased risk of disability, whereas ties with friends or other relatives tend to improve survival. A five-year prospective, population-based study of 295 Swiss octogenarians tested the hypothesis that having a spouse, siblings or close friends, and regular contacts with relatives or friends are associated with longer survival, even at a very old age. Methods: Data were collected through individual interviews, and a Cox regression model was applied to assess the effects of kinship and friendship networks on survival, after adjusting for socio-demographic and health-related variables. Results: Our analyses indicate that the presence of a spouse in the household is not significantly related to survival, whereas the presence of siblings at baseline improves the oldest old's chances of surviving five years later. Moreover, the existence of close friends is a central component in the patterns of social relationships of oldest adults, and one which is significantly associated with survival. Overall, the protective effect of social relationships on survival is more related to the quality of those relationships (close friends) than to the frequency of relationships (regular contacts). Conclusions: We hypothesize that the existence of siblings or close friends may beneficially affect survival, due to the potential influence on the attitudes of octogenarians regarding health practices and adaptive strategies.

(Aging Clin Exp Res 2005; 17: 419-425)

${ }^{\circ} 2005$, Editrice Kurtis

\section{INTRODUCTION}

During the past two decades, numerous studies have analyzed the role of social integration on health (for a review, see Ref. 1). The literature shows the contrasting influences of family members and friendship networks on the survival of old adults. Although a number of research projects have identified a positive association between social relationships and survival (2-6), other published studies have not been able to demonstrate such a connection. For example, that connection has been questioned in the longitudinal study of the elderly in rural North Wales (GB) (7). After multivariate analyses, the authors concluded that there was no evidence that survival was directly affected by social networks. Seeman, Bruce and McAvay (8) go even further, suggesting that ties with children appear to be associated with an increased risk of disability. In their handbook on the psychology of aging, Birren and Schaie (9) also observe that the importance of different types of social ties on survival varies across age groups: for example, ties with friends and relatives assume greater significance for those aged 60 or over, whereas marital status is important for survival only for those less than 60 years old. According to Bowling and Grundy (1), great uncertainty remains about how this association varies between age groups. This uncertainty partly reflects the wide range of conceptual definitions of social relationships, methodologies and data-sets used. In addition, the role of social integration on health may not be universal and may vary by cultural context.

Although there has been ample research on survival determinants into old age, there has been far less on the question of whether there are distinct predictors of survival once within old age. According to the common assumption that individuals who live into their eighties

Key words: Family, longitudinal study, oldest old, social networks, survival.

Correspondence: E. Guilley, PhD, Centre for Interdisciplinary Gerontology (CIG), 59 route de Mon-Idée, 1226 Thônex, Switzerland.

E-mail: edith.guilley@cig.unige.ch

Received September 9, 2003; accepted in revised form October 27, 2004. 
are different from younger elderly people, as they represent "survivors", the role of social relationships on survival may differ in late life. The literature identifies two main characteristics that may affect the social relationships of the oldest old and their associations with survival: a) friends tend to be of similar age so that, as age peers, they also share the same potential physical problems. Thus, friends in late life have difficulty in maintaining frequent face-to-face contact with each other $(10,11)$; b) according to the theoretical model termed socio-emotional selectivity, some of the oldest old "adaptively disengage from some relationships to maximize social and emotional gains and minimize social and emotional risks" (12). These selection processes, resulting in reduced rates of interaction in late life, may modify the association between social networks and mortality. In addition, the fact that research shows differential relations between mortality and social relationships in old age and very old age emphasizes the need for an age- or cohort-specific approach.

Lastly, most longitudinal research on the association between social networks and mortality has been conducted in the USA and Scandinavia (1). Here, we test the effect of social relationships on mortality in a sample of oldest old who participated to a Swiss longitudinal study.

The five-year prospective study of very old Swiss community-dwelling individuals attempts to answer the three following questions: are social networks associated with the survival of the oldest old (aged 80 or over at baseline)? What are the features of the person's social networks (quantitative and/or qualitative) related to her/his length of survival? Which members of a person's network play a role in her/his survival?

\section{METHODS}

\section{Study population}

The participants were members of the Swiss Interdisciplinary Longitudinal Study on the Oldest-Old (Swilso-o), a five-year prospective study which was begun in 1994. This study is briefly described here and in detail elsewhere (13). The participants were randomly selected by the Swiss Cantonal Office of Population from the list of registered community-dwelling octogenarians living in an urban area (Canton of Geneva) and a semi-rural area (central Valais). The sampling frame was stratified by area and gender, and samples of equal size were drawn from each stratum. The selected subjects were contacted by letter and then by phone. Of these subjects, $35 \%$ in Geneva and $41 \%$ in Valais refused to participate. Face-to-face interviews with 340 persons aged 80 to 84 were repeated annually from 1994 to 1999 . The pre-coded structured questionnaire used covered a broad spectrum of topics related to health status and perceived health, social networks, and daily activities.

\section{Measures}

Social relationships were divided into two categories (family and friends). Kinship network was assessed by standard questions about household composition (living alone, with a spouse or with other persons), the existence of living siblings, or children. Contacts with family members (excluding household members) were assessed by three questions: "Do you receive regular visits (at least one a week)?", "Do you regularly visit family members (at least once a week)?" and "Do you talk on the phone regularly (at least once a week) with your family members?" Similar questions - as indicators of the number of friendships - assessed the regularity of contacts (at least one a month) with friends and/or acquaintances. The quality of the friendships was assessed by the question: "Outside your family, do you have a close friend (i.e., a person you love, a person about whose future you feel concern, toward whom you show solidarity?)".

The survival status for each respondent was followed from 1994 to 1999. This follow-up was based on the public records of the Canton of Geneva and Valais town councils, which systematically register information on deaths in their administrative areas. All deaths that occurred between the baseline interview and July 31, 1999 were recorded. This procedure yielded complete records of both survival or death of subjects included in this prospective study, even if they dropped out in the course of the follow-up.

Baseline sociodemographic variables used in the analyses included gender, geographic area (urban or semi-rural), age (from 80 to 84 years) and social status (workingclass or middle/upper-class). In this study, social status was assessed as a dichotomous composite of education, income while professionally active, retirement funds, and other revenues, e.g. private investments.

The health of the oldest old was assessed by functional limitations and depressive symptoms.

- To assess functional limitations, five tasks were adapted from the Katz Activities of Daily Living (ADL) scale: washing, dressing, eating, rising and going to bed, and moving around indoors (14) and three tasks of mobility: going up and down stairs, walking 200 meters, and moving around outside (15). Respondents were asked about their degree of difficulty in performing each activity $(0$ no difficulty, 1 - some difficulty, 2 - unable to perform). The eight items reached a reliability level (Cronbach's alpha) of 0.88 . The functional score was then obtained by summing the degrees of difficulty ( 0 - independent, to 16 - dependent for all activities).

- Depressive symptoms were measured using the Wang Self-Assessing Depression Scale (Wang SADS) (16). It contains ten items (sadness, hopelessness, crying spells, appetite, sleep, fatigue, self-confidence, interest in doing things, irritability and anxiety; Cronbach's alpha $=0.74$ ). The frequency with which these symptoms occurred was 
(C)2005, Editrice Kurtis

Table 1 - Baseline characteristics of sample $(n=295)$.

\begin{tabular}{|c|c|c|}
\hline Domain & Characteristics & $\begin{array}{l}\text { Number (percentage) } \\
\text { or mean (SD) }\end{array}$ \\
\hline Sociodemographic & $\begin{array}{l}\text { Gender: women, } \mathrm{n}(\%) \\
\text { Area: urban, } \mathrm{n}(\%) \\
\text { Age (years), mean (SD) } \\
\text { Social status: middle or upper-class, n (\%) }\end{array}$ & $\begin{array}{l}143(48.5) \\
157(53.2) \\
81.8(1.39) \\
123(41.7)\end{array}$ \\
\hline Health & $\begin{array}{l}\text { Functional limitations (score), mean (SD) } \\
\text { Depressive symptoms (score), mean (SD) }\end{array}$ & $\begin{array}{l}1.34(2.57) \\
41.10(11.14)\end{array}$ \\
\hline Kinship network & $\begin{array}{l}\text { Household composition } \\
\text { - Lives with spouse, n (\%) } \\
\text { - Lives with others, } \mathrm{n}(\%) \\
\text { Has at least one sibling, } \mathrm{n}(\%) \\
\text { Has at least one child, } \mathrm{n}(\%) \\
\text { Receives visits (at least one a week), n (\%) } \\
\text { Pays visits (at least one a week), n (\%) } \\
\text { Talks on phone (at least once a week), n (\%) }\end{array}$ & $\begin{array}{l}153(51.9) \\
23(7.8) \\
212(71.9) \\
236(80.0) \\
166(56.8) \\
90(31.1) \\
203(71.2)\end{array}$ \\
\hline Friendship network & $\begin{array}{l}\text { Has close friends, } \mathrm{n}(\%) \\
\text { Receives visits (at least one a month), } \mathrm{n}(\%) \\
\text { Pays visits (at least one a month), } \mathrm{n}(\%) \\
\text { Talks on phone (at least once a month), } \mathrm{n}(\%)\end{array}$ & $\begin{array}{l}216(73.2) \\
156(54.5) \\
124(43.2) \\
203(70.7)\end{array}$ \\
\hline
\end{tabular}

rated on a 4-point scale (never, rarely, frequently, always). To produce the Wang SADS, the total score was divided by the number of available choices (40) and multiplied by 100 . The score varied from 25 (no symptoms) to 100 (all symptoms).

\section{Statistical analysis}

At baseline interview, 45 persons were not able to answer personally about their social relationships and were consequently excluded from analysis. Thus, analysis was based upon the data supplied by 295 of the 340 baseline respondents. These respondents were more likely to be younger and to have better functional health than the 45 persons excluded, who otherwise were similar by gender. Of the 295 self-respondents who completed the baseline interview in 1994, 84 (28\%) died during the following five years. In 1988-1993, the mortality rate for Swiss citizens aged $80-84$ years was on average $40 \%$ (17). The exclusion of institutionalized persons at baseline and the selection of self-respondents explain the lower mortality rate of participants in this study.

Cox regression models were run using STATA 7.0 (18) to assess the link between social relationships and survival among octogenarians. The outcome variable of interest in this study was survival time in days following baseline interviews. All survivors were regarded as right-censored cases, and their duration of survival was the time elapsing between baseline interviews and the last wave of interviews. The hazard ratio (HR) provided by models may be interpreted as an estimate of the relative risk of death. The proportional hazard assumption of the final Cox model was checked.

Data analysis was divided into two steps. First, the study variables and their univariate relation with survival time were explored. Then, the variables found to be significantly related to survival in the first step were considered in subsequent multivariate modeling. Also examined were interaction effects for social network variables, particularly gender, but no significant interactions were found.

\section{RESULTS}

At baseline, the participants in the present study who answered personally $(n=295)$ were on average 81.8 years old (range 80-84); $48.5 \%$ were female, and $41.7 \%$ were of middle- or upper-class status (Table 1). They had few functional limitations (on average, less than two) and few depressive symptoms (score <50: normal). Half respondents (51.9\%) were living with a spouse; most respondents had children who were still alive $(80.0 \%)$, siblings $(71.9 \%)$ and close friends (73.2\%). Respondents had more frequent contacts with relatives (excluding household members) than with friends and/or acquaintances.

\section{Bivariate models}

Hazard ratios measuring the effects of each variable as the only predictor of the risk of mortality - without adjusting for other variables - are displayed in Table 2. Among the oldest adults' kin network, "has at least one sibling" was the only variable with positive effect on the length of life. Living with a spouse vs living alone was associated with higher risk of death. No significant relation was found between survival and having at least one child or having contacts with relatives. The bivariate analyses also indicated that the oldest old who have close friends or regular face-to-face contacts (i.e., receive or pay visits) with friends and/or acquaintances have a lower risk of death. The quality of social relationships, assessed by the presence or absence of a 
Table 2 - Cox regressions between time to death and individual variables measured at baseline $(n=295)$.

\begin{tabular}{|c|c|c|c|}
\hline \multirow[b]{2}{*}{ Domain } & \multirow[b]{2}{*}{ Variables } & \multicolumn{2}{|c|}{ Bivariate models } \\
\hline & & Hazard ratio & $\boldsymbol{p}$ \\
\hline \multirow[t]{4}{*}{ Sociodemographic } & Gender (women) & $0.54^{* *}$ & 0.006 \\
\hline & Area (urban) & 1.13 & 0.564 \\
\hline & Age in years & $1.35^{* * * *}$ & 0.000 \\
\hline & Social status (middle/upper-class) & 0.88 & 0.565 \\
\hline \multirow[t]{2}{*}{ Health } & Functional limitations & $1.14^{* * * * *}$ & 0.000 \\
\hline & Depressive symptoms & $1.02^{* * *}$ & 0.007 \\
\hline \multirow[t]{8}{*}{ Kinship network } & Household composition & & \\
\hline & - Lives with spouse vs lives alone & $1.99^{* * *}$ & 0.005 \\
\hline & - Lives with others vs lives alone & 0.82 & 0.715 \\
\hline & Has at least one sibling & $0.53^{* * *}$ & 0.004 \\
\hline & Has at least one child & 0.96 & 0.883 \\
\hline & Receives visits (at least one a week) & 1.09 & 0.713 \\
\hline & Pays visits (at least one a week) & 1.08 & 0.746 \\
\hline & Talks on the phone (at least once a week) & 0.94 & 0.807 \\
\hline \multirow[t]{4}{*}{ Friendship network } & Has close friends & $0.50^{* * *}$ & 0.002 \\
\hline & Receives visits (at least one a month) & $0.64^{*}$ & 0.042 \\
\hline & Pays visits (at least one a month) & $0.60^{*}$ & 0.029 \\
\hline & Talks on the phone (at least once a month) & 0.67 & 0.079 \\
\hline
\end{tabular}

close friend, is more associated with the length of life of the oldest old than with regular face-to-face contacts with friends/acquaintances - a quantitative indicator.

\section{Cox multivariate analysis of factors related} to mortality

A final model was examined which simultaneously included all the variables found to have significant effects $(p<0.05)$ in the previous individual models shown in Table 2. Sociodemographic characteristics - age and gender - appeared to be significantly related to survival (Table 3), confirming that the risk of death increases with age and that men have a higher risk of mortality. As expected, both functional limitations and depressive symptoms influenced the survival of the oldest old. Adjustments for baseline sociodemographic and health covariates suppressed the association between living with a spouse and mortality $(\mathrm{HR}=1.67, p=0.080)$, partly because of the substantial association between household composition and gender (chi-square $=59.8 ; p<0.001$ ). When

Table 3 - Cox multivariate analysis of factors related to mortality $(n=295)$.

\begin{tabular}{|c|c|c|c|}
\hline Baseline variables & Hazard ratio & $95 \% \mathrm{CI}$ & $p$ \\
\hline $\begin{array}{l}\text { Sociodemographic } \\
\text { Gender (women) } \\
\text { Age }\end{array}$ & $\begin{array}{l}0.56^{*} \\
1.26^{* * *}\end{array}$ & $\begin{array}{l}0.32-0.97 \\
1.07-1.49\end{array}$ & $\begin{array}{l}0.040 \\
0.006\end{array}$ \\
\hline $\begin{array}{l}\text { Health } \\
\text { Functional limitations } \\
\text { Depressive symptoms }\end{array}$ & $\begin{array}{l}1.11^{*} \\
1.02^{*}\end{array}$ & $\begin{array}{l}1.01-1.22 \\
1.00-1.04\end{array}$ & $\begin{array}{l}0.024 \\
0.037\end{array}$ \\
\hline $\begin{array}{l}\text { Kinship network } \\
\text { Household composition } \\
\text { - Lives with spouse vs lives alone } \\
\text { - Lives with others us lives alone } \\
\text { Has at least one sibling }\end{array}$ & $\begin{array}{l}1.67 \\
0.67 \\
0.56^{*}\end{array}$ & $\begin{array}{l}0.94-2.98 \\
0.23-1.99 \\
0.35-0.89\end{array}$ & $\begin{array}{l}0.080 \\
0.472 \\
0.014\end{array}$ \\
\hline $\begin{array}{l}\text { Friendship network } \\
\text { Has close friends } \\
\text { Receives visits (at least one a month) } \\
\text { Pays visits (at least one a month) }\end{array}$ & $\begin{array}{l}0.60^{*} \\
0.69 \\
1.16\end{array}$ & $\begin{array}{l}0.37-0.99 \\
0.38-1.22 \\
0.61-2.19\end{array}$ & $\begin{array}{l}0.046 \\
0.202 \\
0.653\end{array}$ \\
\hline
\end{tabular}


differences in mortality rates were adjusted for sociodemographic and health-related variables, the effect of regular face-to-face contacts on survival disappeared. Those visiting their friendship network were in fact less likely to have functional limitations (incidence rate ratio $=0.39$, $p<0.001$ ). The other effects of kinship and friendship networks remained statistically significant: a decreased mortality risk was associated with having siblings $(\mathrm{HR}=0.56$, $p=0.014$ ) and those with close friends had a lower risk of death $(\mathrm{HR}=0.60, p=0.046)$.

\section{DISCUSSION}

Our analysis indicates that the existence of close friends is associated with survival of the oldest old. This affective component of social relationships seems to have a more important effect on the survival of the oldest old than the quantitative dimensions of friendship. Hanson et al. (19) also tested the effect of the quality of friendship contacts, together with their frequency, on survival, and found that emotional ties were more important than the number of friendship contacts. This may be explained by the fact that contact variables are not the best indicators of the functions of friendship, because the emotional benefits may be independent of the number of face-to-face interactions (20). Intimate ties also have an influence on other central aspects of late life, by affecting life style (19) and well-being and acting as a buffer against stressful life events (21).

Our results contribute toward underlining the importance of intimate relationships in the lives of the oldest old. This study did not examine the duration of friendships, so we do not know whether old friendships differ from more recent ones. Similarly, we are unable to say which precise functions of close friendships are central for the survival of very old women and men. However, the literature on friendships in later life gives clues to the mechanisms by means of which friendship networks are related to longevity. In a qualitative study of older women, respondents (77 years old on average) were asked to explain what "close friend" meant to them (22). The author found that the majority $(81 \%)$ defined a close friend as a confidant. Bould, Sanborn and Reif (23), in their research on people aged 85 and over in the USA, suggest that the existence of a confidant may be essential for the development of effective coping strategies which, in turn, reduce the risk of death (24). It is worth mentioning that this effect of personal coping resources did not disappear when additional adjustments for physical limitations, self-rated health, smoking and intake of alcohol were included.

Our study also revealed that the presence of a brother or sister at baseline was related to the oldest old's chances of surviving five years. To our knowledge, only one study (25) tested the effect of siblings on survival, with similar results. One hypothesis, which our data un- fortunately cannot verify, is that siblings are a source of affective ties and hence have the same effect on survival as close friends. Indeed, siblings often operate as confidants in old age (26) and contribute to the well-being of the elderly (27). With age, feelings of closeness to siblings increase (28). The "siblings" effect may also reflect a genetic influence: those still having surviving siblings may belong to high-longevity families. One study based on identical and fraternal twins supports the genetic hypothesis, suggesting the significant influence of genetic effects on variations in longevity (29).

In our analyses, siblings and friends seemed to play a more important protective role on the oldest old's survival than did their descendants. Surprisingly, no statistically significant effect of having a child was found in this study. The absence of a relationship between the survival of the oldest old and the existence of children is surprising. Connidis and Davies (26) showed that increasing age may be associated with an increased propensity to name children as companions. This suggests that children play a social role in the oldest old's lives which enhances the survival of their parents, as demonstrated by Silverstein and Bengston (4). According to these authors, close intergenerational relations with adult children buffer the elevated mortality risks associated with becoming widowed. It is also possible that the weak predictive power of the variable "children" in our study reflects the insensitivity of the measure used: the existence of children may not in itself ensure an emotional link between very old parents and their children. Because they are formally prescribed and governed by cultural obligations and responsibilities, interactions with children do not necessarily imply an emotional dimension (30). Having children may also be associated with both benefits and strains. Consequently, they may provide less unequivocal psychological reinforcement, compared with relationships with friends (31).

Many epidemiological studies have found a relationship between being married and lower rates of mortality for those less than 60 years old (32). However, marital status is not shown to be a predictor of longer survival among older adults $(4-7,33)$. Although our study did not find that living arrangements were significantly related to the likelihood of mortality, living with a spouse $v$ s living alone operated in an astonishing direction ( $\mathrm{HR}=1.67 ; p=0.068$ ). One explanation is the instrumental support that the spouse of an impaired person often provides. Caring for the impaired can produce a variety of stressors and affect the health of the caregiver for young old people (34). The burden that care-giving represents may be stronger in late life: a study on very old couples indicated that spouse caregivers are in poorer physical health than non-caregivers (35). Moreover, one major shift is the growing prevalence of widowhood at very old ages. As a consequence, baseline household composition is an unstable parameter, highly exposed to change over time. In 
the Swilso-o study, $22.2 \%$ of those who reported living with a spouse at baseline had seen their living situation modified during the five-year follow-up, and these relocations may have been detrimental for the health of very old persons. Another explanation is that persons living with a spouse and who are in ill health may be able to remain in the community longer - and therefore participate in the study - than persons in ill health who do not have a spouse to care for them. As a consequence, the population with spouses may be "enriched" with persons in ill health who are at greater risk of death.

Our findings must be appreciated within the context of several limitations. All explanatory and controlled variables were measured at baseline. Explanatory variables like social networks may change over time, and these changes - such as the death of a close relative - may also have an influence on the risk of mortality. Second, non-response in our study was higher in the older and less healthy subjects. This selective non-response may have biased the association between survival and social relationships. Lastly, according to the rough rule of keeping no more than about $\mathrm{m} / 10$ predictors in a multiple regression model, where $m$ is the number of uncensored events in the sample (here, $\mathrm{m}=84$ ) (36), our multivariate model is slightly over-fitted. However, the suppression of non-significant effects (i.e., household composition, subjects receive and pay visits to friends and/or acquaintances) which results in a model with six factors, hardly changes the hazard ratio of the remaining variables significantly related to mortality.

\section{CONCLUSIONS}

We found that having close friends and/or at least one sibling is associated with lower risks of death, and this association remains statistically significant when adjusted for functional limitations and symptoms of depression. However, these findings do not signify that we have identified the direct influence of social networks on mortality. Some studies indicate that social networks provide access to better health information which, in turn, decreases the risk of death (9). Social networks may also protect against various kinds of stressful events by promoting coping strategies, such as a sense of control and self-efficacy $(9$, 37). This suggests that the positive association between close friends or siblings and survival reflects indirect pathways by means of which social ties affect mortality risks via their effects on health practices and adaptive strategies.

\section{ACKNOWLEDGEMENTS}

This research was funded by the Swiss National Science Foundation under the Priority Program, "Switzerland: towards the future" (No 5004-058534/058536). Thanks are due to the Health and Social Action Department of the Republic and Canton of Geneva and to the Health Department of the Canton of Valais for financial support. The authors thank C. Cordonier for his important contribution to data collection, and also Dr. B. Grab (University Hospital of Geneva) for advice on statistical analyses and M. Bell for editorial assistance.

\section{REFERENCES}

1. Bowling A, Grundy E. The association between social networks and mortality in later life. Rev Clin Gerontol 1998; 8: 353-61.

2. House J, Landis KR, Umberson D. Social relationships and health. Science 1988; 241: 540-5.

3. Seeman TE, Kaplan GA, Knudsen L, Cohen R, Guralnik J. Social network ties and mortality among the elderly in the Alameda County Study. Am J Epidemiol 1987; 126: 714-23.

4. Silverstein M, Bengston VL. Do close parent-child relations reduce the mortality risk of older parents? J Health Soc Behav 1991; 32: 382-95.

5. Steinbach U. Social networks, institutionalization, and mortality among elderly people in the United States. J Gerontol 1992; 47: 183-90.

6. Wolinsky FD, Johnson RL, Stump TE. The risk of mortality among older adults over an eight-year period. Gerontologist 1995; 35: 150-61.

7. Shahtahmasebi S, Davies R, Wenger GC. A longitudinal analysis of factors related to survival in old age. Gerontologist 1992; 32: 404-13.

8. Seeman TE, Bruce ML, McAvay GJ. Social network characteristics and onset of ADL disability: MacArthur Studies of Successful Aging. J Gerontol 1996; 51: 191-200.

9. Birren JE, Schaie KW. Handbook of the psychology of aging, 4th ed. San Diego: Academic Press, 1996.

10. Johnson CL, Troll LE. Constraints and facilitators to friendships in late late life. Gerontologist 1994; 34: 79-87.

11. Johnson CL, Barer M. Life beyond 85 years - the aura of survivorship, 1st ed. New York: Springer Publ. Co., 1997.

12. Carstensen LL. Selectivity theory: social activity in life-span context. Annu Rev Gerontol Geriatr 1991; 11: 195-217.

13. Lalive d'Epinay C, Cavalli S, Spini D. The death of a loved one: impact on health and relationships in very old age. Omega 2003; 47: 265-84.

14. Katz S, Ford AB, Moskowitz RW, Jackson BA, Jaffee MW. Studies of illness in the aged. The index of ADL: a standardized measure of biological and psychosocial function. JAMA 1963; 185: 94-101.

15. Rosow I, Breslau N. A Guttman health scale for the aged. J Gerontol 1966; 21: 556-9.

16. Wang RIH, Treul S, Alverno L. A brief self-assessing depression scale. J Clin Pharmacol 1975: 163-7.

17. Office Fédéral de la Statistique. Tables de mortalité 1988/93. Berne: OFS; 1996.

18. StataCorp. Stata Statistical Software: Release 7.0. College Station, TX: Stata Corporation, 2001.

19. Hanson BS, Isacsson SO, Janzon L, Lindell SE. Social networks and social support influence mortality in elderly men - the prospective population study of 'Men Born in 1914', Malmo, Sweden. Am J Epidemiol 1989; 130: 100-11.

20. Blieszner R. Developmental processes of friendship. In Adams RG, Blieszner R, eds. Older adult friendship. Structure and process. Newbury Park: Sage, 1989: 108-26.

21. Brown GW, Harris T. Social origins of depression. A study of psychiatric disorders in women. London: Tavistock Publications, 1978.

22. MacRae H. Strong and enduring ties: older women and their friends. Can J Aging 1996; 15: 374-92.

23. Bould S, Sanborn B, Reif L. Eighty-five plus. The oldest old. Belmont, CA: Wadsworth Publishing Company, 1989. 
24. Penninx BWJH, Van Tilburg T, Kriegsman DMW, Deeg DJH, Boeke AJP, van Eijk JTM. Effects of social support and personal coping resources on mortality in older age: the Longitudinal Aging Study Amsterdam. Am J Epidemiol 1997; 146: 510-9.

25. Barrett-Connor E, Wingard DL. Heart disease risk factors as determinants of dependency and death in an older cohort: the Rancho Bernardo study. J Aging Health 1991; 3: 247-61.

26. Connidis IA, Davies L. Confidants and companions: choices in later life. J Gerontol 1992; 47: 115-22.

27. Hilkevitch Bedford V. Sibling relationships in middle and old age. In Blieszner R, Hilkevitch Bedford V, eds. Handbook of aging and the family. Westport: Greenwood Press, 1995: 201-22.

28. Cicirelli VG. Sibling influence throughout the lifespan. In Lamb ME, Sutton-Smith B, eds. Sibling relationships: Their nature and significance across the lifespan. Hillsdale, NJ: Lawrence Erlbaum, 1982.

29. Ljungquist B, Berg S, Lanke J, McClearn G, Pedersen NL. The effect of genetic factors for longevity: a comparison of identical and fraternal twins in the Swedish Twin Registry. J Gerontol 1998; 53: 441-6.

30. Mullins LC, Smith R, Colquitt R, Mushel M. An examination of the effects of self-rated and objective indicators of health condition and economic condition on the loneliness of older persons. J Appl Gerontol 1996; 15: 23-37.

31. Antonucci TC. Social supports and social relationships. In Binstock $\mathrm{RH}$, George LK, eds. Handbook of aging and the social sciences, 3rd Ed. San Diego, CA: Academic Press, 1990.

32. Bosworth HB, Schaie KW. The relationship of social environment, social networks and health outcomes in the Seattle Longitudinal Study: two analytical approaches. J Gerontol 1997; 52: 197-205.

33. Sugisawa H, Liang J, Liu X. Social networks, social support, and mortality among older people in Japan. J Gerontol 1994; 49: 313.

34. Pearlin LI, Mullan JT, Semple SJ, Skaff M. Caregiving and the stress process: an overview of concepts and their measures. Gerontologist 1990; 30: 583-91.

35. Wallsten SS. Effects of caregiving, gender and race on the health, mutuality and social supports of older couples. J Aging Health 2000; 12: 90-111.

36. Harrell FE, Lee KL, Mark DB. Multivariable prognostic models: issues in developing models, evaluating assumptions and adequacy, and measuring and reducing errors. Stat Med 1996; 15: 361-87.

37. Adelmann PK. Multiple roles and psychological well-being in a national sample of older adults. J Gerontol 1994; 49: 277-85. 